\title{
Exploring Cultural Intelligence Skills among International Postgraduate Students at a Higher Education Institution
}

\author{
Faizah Idrus ${ }^{1}$ \\ ${ }^{1}$ Kulliyyah of Education, International Islamic University Malaysia \\ Correspondence: Faizah Idrus, Kulliyyah of Education, International Islamic University Malaysia, Jalan Gombak, \\ Kuala Lumpur, Malaysia.
}

Received: January 15, 2021

Accepted: March 9, 2021

Online Published: March 10, 2021

doi:10.5430/ijhe.v10n4p220

URL: https://doi.org/10.5430/ijhe.v10n4p220

\begin{abstract}
Recognising the importance of Cultural Intelligence (CQ) is crucial to any Higher Education Institution (HEI) hosting international students. Thus, the investigation seeks to explore postgaduates experiences, perceptions, challenges and strategies in accommodating their friends' from diverse cultural backgrounds in their daily academic and social lives. A qualitative research design was employed in that 15 international postgraduate students from 5 faculties were interviewed (using semi-structured interview protocol) in relation to their experience, understanding and behaviour towards cultural knowledge and skills. Rigourous thematic analysis following Braun \& Clark (2006) was carried out. The main findings indicated that international students faced huge challenges during the acculturation and adaptation processes trying to be accepted or to blend in, unaware of Cultural Intelligence. Positive reactions from international students prevailed. External and internal factors posed as huge setback to their success in communication and studies. It can be concluded that with prior awareness and understanding of CQ and cultural diversity, international students could be more prepared in adjusting to academia, thus be more successful in their studies. The findings of this study are of paramount importance to HEIs, International and Student Admission offices around the globe.
\end{abstract}

Keywords: Cultural Intelligence (CQ), cultural diversity, acculturation, postgraduate, international students, higher education institutuions

\section{Introduction}

\subsection{International Students' Adaptation to Host Country}

A well-rounded education today requires students to not only perform well academically but to be equipped with cross-cultural knowledge due to the rising demands for internationalization and globalization. This is evident with the increasing number of students pursuing their higher education abroad suggests a strong need for social skills and cultural understanding to aid them in their adaptation to the host country. Once accepted to study abroad, potential students will leave their homes to embark on a whole new journey, away from their loved ones. However, many international students have travelled to their host country, unprepared, physically, emotionally or perhaps financially, and with inadequate knowledge and information of the target country. If these are not sufficiently managed, the students would unquestionably be facing serious challenges in their survival in their new place. Thus, with new environment and circumstances, the importance of cultural intelligence is indubitably inherent.

Undoubtedly, the current rapid growth of international students at higher education institutions has brought many benefits to the overall teaching and learning processes. Not only that they add to the diversity of cultural practices in the educational setting, the international students also help to maintain academic reputation besides providing higher education institutions with large financial benefit (Paltridge, Mayson, and Schapper, 2012). This is relevant to the current educational context specifically in Asia in that the enrolment of international students at higher education institutions does not only serve as a profit-making business but to help develop a competitive learning environment. With the increasing number of international students in foreign countries, it suggests a valid realisation on the need to be culturally intelligent where the students are able to adapt and function well in an unfamiliar environment as a result of they being able to respect and value cultural differences. Besides, many scholars have also agreed that cultural intelligence (CQ) is one of the latest contributions on intelligence in which it is often studied along the other different types of intelligences including emotional, social and interpersonal. With $C Q$, the interactions and 
socialisations between people across the world are made more successful and favourable.

For many years, people have debated about the challenges faced by international students who live in foreign lands (Zuria, Salleh, Saemah and Noriah, 2010; Gapsalamov et al., 2016). Lin and Yi (1997) as cited in Yusliza and Chelliah (2010) agree that the international students very often become the subject to discrimination, dietary restrictions and preferences, cultural conflicts as well as loneliness which make the adaptation process even more difficult and challenging. Besides, existing literature suggests that most of the international students are not able to adapt to a new environment due to their inability to fit in with different lifestyles, language and culture of the host country (Baklashova and Kazakov, 2016). This trend at the same time describes the acculturative stress experienced by them where they usually fail to change their attitudes in accordance to the new cultural practices. Additionally, many believe that was the result of one's lack of awareness of the newly introduced concept, cultural intelligence (Brancu et al., 2016). These points are key to the investigation of the current study.

\subsection{Significance of the Investigation}

The cultural intelligence (CQ) field is relatively new to many. It emerged as a vital field in the areas of business management at its inception, and then spread out to many other different areas such as Human Resource Management, Education, Finance and others. With the lack of understanding of CQ, the international students' adaptation to the host country is hence, considered problematic. Thus, looking at the challenges faced by the international students as well as their lack of awareness of CQ, it is evident to suggest the importance of conducting this research. Knowing the fact that CQ is relatively a new concept introduced in 2002 (Ott and Michailova, 2016), not many studies have been found to extensively explain the importance of CQ on adjustment process in academic setting (Nur Arief, et. al, 2015). The present study discusses and argues international students' adaptation to a new environment with regard to the CQ concept. It highlights the need for one to be culturally intelligent and fulfilled the specific dimensions of CQ which include; metacognitive, cognitive, motivational and behavioural as a means to overcome challenges while adapting to an unfamiliar setting. As the issue of CQ is yet to be researched widely, the present study suggests a novel contribution to the existing literature which in other words, helps to fill the research gap with some beneficial new findings. Correspondingly, this study will not only benefit the students but also staff in academic institutions. Not only that the students need to be culturally intelligent, their lecturers too need to be sensitive to others' cultures. This is pertinent to ensure that the students engage in meaningful learning as a result of being knowledgeable and understand how CQ works.

This current study specifically intends to investigate international postgraduate students' social and academic challenges as well as their acculturation processes in a selected Higher Education Institution (as a case study) in tolerating with different cultural practices. Briefly, this study seeks to examine international students' perceptions of cultural diversity, explore the challenges faced to be culturally intelligent and identify the strategies used to cope with those challenges.

\section{Review of Related Literature}

\subsection{What is Cultural Intelligence?}

Cultural Intelligence's concept has been discussed in various ways by eminent scholars and researchers. It was developed as a multidimensional construct and research were carried out to study its relationship with other types of intelligences. Some have quoted it as an ability to manage and function in a multicultural setting. Others mentioned CQ as a set of skills required to handle cross cultural situations and to be able to create positive impression. Earley and Ang (2003) defined CQ as an individual's potential to adjust and adapt in cross cultural environment. In consistent with this definition Ang et al. (2007); Ng et al. (2009) described CQ as a mental state of an individual which helps one to deal effectively with individuals and situations from various cultures. On the other hand, Peterson (2004) opined that CQ is an ability that requires using of specific skill set and qualities that are in tune with the values and attitudes of people with whom the interaction pattern is set. His approach is based on the concept of multiple intelligences. While Thomas and Inkson (2004) suggested that Cultural Intelligence helped in assisting to increase and build cultural competency in managers, leaders and teams of today's organizations. It is described as a multidimensional competency encompassing cultural knowledge and has a significant impact on leader performance and team performance. The main issue here is, CQ is more than just being culturally aware and sensitive to others' cultures. It is the ability to relate to culturally diverse situations and work effectively in them.

Many existing literatures on CQ uncovered the role of CQ on expatriates. Aldhaheri (2017) asserted that the school leaders with high CQ were better at adapting to their leadership style in the Abu Dhabi education sector. This, Aldhaheri elaborated was due to their culturally-sensitive personalities and behaviours, besides they were able to 
stablish good communication with the locals. Similarly, Ziyatdinova (2017) argued that leaders with good understanding of CQ concept usually portrayed successful leadership skills. Ersoy (2014) agreed that the leaders' cultural awareness, motivational and behavioural adaptation together with their ability to maintain effective interactions with the locals were among the important keys to ensure leadership effectiveness. Their findings proved the importance of CQ on leaders' successful management.

Besides, Stockert (2015) who studied the role of personality and cultural intelligence in expatriate adjustment of U.S. military on foreign assignment agreed that the expatriate's CQ helped them a lot in the adjustment of US military. Chen (2015) also confirmed that CQ influenced students' psychological well-being and employability. In addition, Ramalu, Wei and Raduan (2011) reported that CQ is important to aid in expatriates' cross-cultural adjustment. They revealed that both metacognitive and motivational CQ contributed the most in the expatriates' cross-cultural adjustments while the interaction adjustment was positively correlated to the expatriates' metacognitive, cognitive and motivational CQ. Similarly, Harrison and Brower (2011) and Idrus (2015) reported that the students with high CQ faced fewer problems in cross-cultural adjustments and were able to cope with homesickness. In this current study, the multidimensional CQ model proposed by Ang, et. al (2007) is used as a framework to describe international and local students' dilemma and challenges in adapting to a new environment.

\subsection{Theoretical Framework}

CQ model focuses on four dimensions which are metacognitive, cognitive, motivational and behavioural. Metacognitive CQ refers to mental activities that take place as a result of one's understanding of other cultures. The individuals with high metacognitive CQ usually modify their personal assumptions during intercultural interactions to suit others' cultural beliefs. On the other hand, cognitive CQ refers to the knowledge about cultural practices, norms and traditions. They possess broad knowledge of others hence are able to identify similarities and differences between cultures. Motivational CQ reflects the interests and enthusiasm in knowing or learning about other cultures. People with high motivational CQ usually put very much effort to understand other cultures. The last dimension is behavioural CQ where it suggests individual's successful ability in using correct verbal and non-verbal actions of other cultures. They are able to use the correct terminology, tone and body language during intercultural interactions.

To further elaborate, CQ model originates from the theory of multiple-loci of intelligences. Using Sternberg's (1986) multiple-loci of intelligences, Earley and Ang (2003) extended the concept of 'loci' of intelligences into four CQ dimensions. Sternberg (1986) stated that intelligence is connected to different 'loci' which includes biology, cognition, motivation and behaviour (Aldhaheri, 2017). Following the idea, Earley and Ang (2003) used the four different 'loci' to explain one's cultural experiences. Besides, Chen (2015), exemplifies a 'theoretical extension of Gardner's (1983) multiple facets of intelligence'. Unlike the other types of intelligences such as emotional intelligence (EQ), social intelligence (SQ) and cognitive intelligence (IQ), CQ is different as it involves cultural continuum (Solomon and Steyn,2017). Evidently, there are many theories on the composition of CQ components. For example, Early and Ang (2003) suggest CQ to consist of cognitive, motivational and behavioural ability while Earley and Mosakowski (2004) propose other components which include head, body and heart. In contrast, Thomas (2006) confirms that the CQ model includes knowledge, mindfulness and behaviour. Ekelund, Cerdin, Pekerti, Aycan, Thomas, Au, Elron, Stahl, Ravlin, Poelmans, Brislin, Maznevski, and Lazarova (2008) mentioned three components of CQ which include cultural knowledge, cross-cultural skills, and cultural meta-cognition. Finally, Ang, et. al (2007) conclude that the four components of CQ are metacognitive, cognitive, motivational and behavioural. The concept of CQ can further be represented in Figure 1 (Lovvorn,2011). 


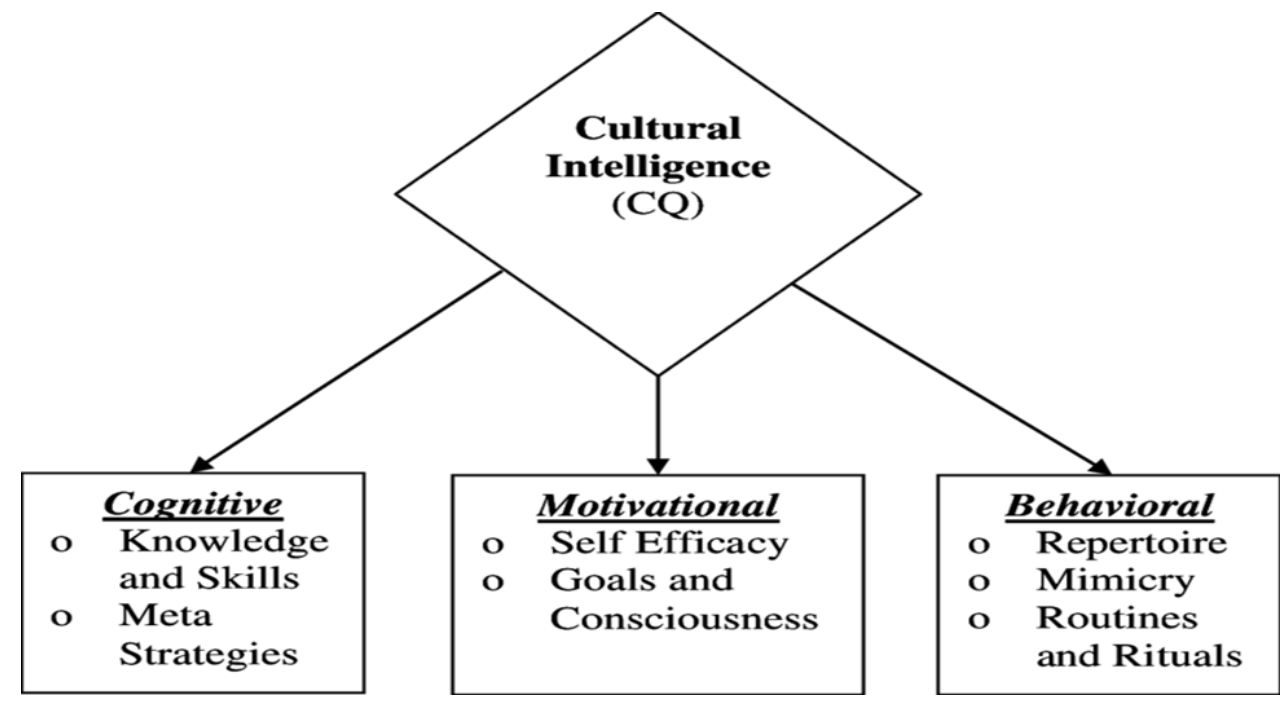

Figure 1. The conceprt of CQ (As cited in Lovvorn, 2011, p.277)

\subsection{Challenges Faced by International Students}

Many studies have been found to concentrate on the challenges faced by the international students. Malaklolunthu and Selan (2011) who studied the adjustment problems among international students in Malaysia mentioned that several common problems experienced by students included academic, religious, personal, social, financial and language adjustment. They confirmed that most of the international students suffered from the academic, religious, personal and social adjustment while very few had financial and language problems. However, they did not specify the stages of studies of the international students as undergraduates and postgraduates have different needs, thus challenges would be different too. On the contrary, Gebhard (2012), mentioned that many international students claimed academic reading to be burdensome. In the same vein, Unruh (2015) reported that the international students also suffered from low level of English proficiency, cultural differences and racial biases where racial biases were reported to be among the major problem confronting the international students.

Additionally, Evivie (2009) reported that the problems encountered by African international students in the United States include; (1) financial issues, (2) alienation, (3) homesickness, (4) lack of social support, (5) cultural differences and (6) health problems. Evivie concluded that the most overwhelming challenges were financial problems and cultural differences. Surprisingly, the findings also revealed that the students were not severely discriminated as opposed to what had been reported in the existing literature. In contrast, Lin and Scherz (2014) argued that many international students did not have opportunities to interact and socialize with the locals due to linguistic restrictions. The language problems according to Lin and Yi (1997) as cited in Alghamdi and Otte (2016) could cause psychological and social difficulties of the international students.

Alghamdi and Otte (2016) as well as Idrus (2014) added that three major problems faced by the international students were academic, social and financial issues. They elaborated that the lack of English proficiency was detrimental to international students' overall achievement where it could limit the socialisation with the locals besides impacting the students' learning process. Notwithstanding, English proficiency only applies mostly in countries where English is their first language of communication. The international students too admitted that the locals usually refused to make friends with them due to similar problem. Being labelled as a temporary visitor in the foreign country, Paltridge, Mayson, and Schapper (2012) claimed that the international students usually became the subject of social exclusion. In addition, Alavi and Syed (2011) revealed that the most challenging problems for international students at University of Technology Malaysia (UTM) were social and recreational and also curriculum and methods of teaching. Seemingly, very few students voted 'health related problems' to be among the biggest challenges they experienced in a foreign country.

\subsection{Acculturation Process}

Acculturation is the phenomenon of the value, attitudinal, and behavioral changes of individuals who come into continuous contact with another culture (Berry, 1980). Cole (2019) mentioned that the criterion for acculturation is the presence of bicultural influences, regardless of the relative strengths of the two cultures. Thus, one possible scenario is in an immigrant setting, where a person migrates into another culture. Evidently, it is a process through 
which a person or group from one culture comes to adopt the practices and values of another culture, while still retaining their own distinct culture. This process is most commonly discussed regarding a minority culture adopting elements of the majority culture, as is typically the case with immigrant groups that are culturally or ethnically distinct from the majority in the place to which they have immigrated. However, acculturation is a two-way process, so those within the majority culture often adopt elements of minority cultures with which they come into contact. It can happen at both group and individual levels and can occur as a result of in-person contact or contact through art, literature, education or media. In the case of international students, acculturation is temporary in that they will resume their own cultural practices once they are back at their homelands and their studies are completed. Hence, they cease to practice the cultural norms of their host country.

\subsection{International Students' Adaptation Strategies}

Other studies also focused on international students' adaptation strategies. According to Baklashova and Kazakov (2016), a few probable strategies to aid in the students' adaptation process included; (1) using educational resources as the problem-solving strategy, (2) dormitory and students' activities, (3) language support, (4) psychological support and (5) students' organizations. Besides, Pare and Tsay (2002) mentioned that establishing a specific organization for the international students could foster cultural and social integration between international and local students. Akhtaruzzaman and Hoque (2011) suggested that a continuous practice to interact using the English language helped to improve international students' language proficiency which could enhance their socialisation with the locals.

To add, Flanja and Gâz (2011) revealed that several coping strategies used by the international students were self-motivation, socialisation, positive thinking and also participation in cultural activities. Likewise, Nisreen and Shin (2017) reported that the three most helpful strategies were improving language, time management and using the available resources. One other strategy suggested by the students was, mixing with the people from the same and different cultures (Tseng and Newton, 2002). This way, they were able to understand the host culture better (Zeng, 2017). Other protective factors also included self-esteem and social support to reduce the impact of acculturation stress as well as loneliness experienced by the international students.

\section{Methodology}

\subsection{Research Design}

A qualitative research design was used in this investigation in that individual semi-structured interviews were employed to collect data (in IN A). This method was used as it offered comprehensive strategy to be used about the topic discussed through the respondents' individual experiences. The constructivist paradigm was applied in this study in which the researcher believed that new knowledge or reality could be constructed through interactions between human beings. Through constructivism, the researcher was able to discover the underlying meanings from the respondents' experiences.

\subsection{Setting}

This study was conducted at a selected International Higher Education Institution (IN A is used throughout this study indicating the representation of the selected Institution) in the capital city of Kuala Lumpur, Malaysia. The overall population of IN A is 30,649 coming from 117 countries who pursued their studies at either undergraduate or postgraduate level. International students are made up of about $15 \%$ of the total population. With the large number of international students in IN A, making the university a place with diverse cultural practices and lifestyles.

\subsection{Sampling Technique}

The respondent were chosen from students of different countries who had different living styles and experiences in Malaysia. Through purposive sampling technique, only respondent with (1) at least two years of living experiences in Malaysia and were (2) registered as postgraduate students; were selected to become the respondents for this study. The minimum period of living in Malaysia was important to indicate the respondent' familiarity with the Malaysian environment, besides suggesting a fair condition for each participant. Additionally, the students were chosen in this study to understand their challenging academic tasks, hence getting to know about the ways they cope with the challenges while maintaining academic success was helpful to explain how the coping strategies work. All the respondents who fulfilled the mentioned criteria with diverse age and gender were included in this study. However, respondents with serious problems or were registered as part-time students were excluded from participating in this study. The inclusion and exclusion criteria were important to remove the influence of specific confounding factors that can affect the trustworthiness of the research outcome. 


\subsection{Respondents}

Table 1. provides a detailed description of each respondent.

\begin{tabular}{|c|c|c|c|c|c|c|}
\hline No. & Name & Gender & Country of Origin & Age & Faculty & No Of years in Malaysia \\
\hline 1. & PG 1 & $\mathrm{M}$ & Nigeria & 25 & Engin & 2 \\
\hline 2. & PG 2 & M & Bangladesh & 25 & Engin & 2 \\
\hline 3. & PG 3 & $\mathrm{~F}$ & Peru & 27 & HS & 2 \\
\hline 4. & PG 4 & $\mathrm{~F}$ & Indonesia & 24 & ICT & 3 \\
\hline 5. & PG 5 & M & Yemen & 21 & ICT & 2 \\
\hline 6. & PG 6 & M & Algeria & 20 & Engin & 2 \\
\hline 7. & PG 7 & $\mathrm{~F}$ & Turkey & 21 & HS & 2 \\
\hline 8. & PG 8 & $\mathrm{~F}$ & Albania & 21 & Econs & 2 \\
\hline 9. & PG 9 & M & Djibouti & 20 & Edu & 2 \\
\hline 10. & PG 10 & M & Saudi Arabia & 20 & Econs & 2 \\
\hline 11. & PG 11 & $\mathrm{~F}$ & China & 25 & Edu & 2 \\
\hline 12. & PG 12 & M & Uganda & 25 & Engin & 3 \\
\hline 13. & PG 13 & M & Tanzania & 24 & HS & 3 \\
\hline 14. & PG 14 & $\mathrm{~F}$ & Thailand & 24 & Econs & 2 \\
\hline 15. & PG 15 & $\mathrm{~F}$ & Maldives & 25 & HS & 2 \\
\hline \multicolumn{7}{|c|}{ PG - Postgraduate } \\
\hline \multirow{5}{*}{\multicolumn{2}{|c|}{ Faculties Key: }} & \multicolumn{5}{|c|}{ HS - Human sciences } \\
\hline & & \multicolumn{5}{|c|}{ Engin - Engineering } \\
\hline & & \multicolumn{5}{|c|}{ Econs - Economics } \\
\hline & & \multicolumn{5}{|c|}{ ICT - Information and Communication Technology } \\
\hline & & \multicolumn{5}{|c|}{ Edu - Education } \\
\hline
\end{tabular}

\subsection{Data Collection Procedures and Ethical Considerations}

The data collection procedure started with the information gathered via phone calls at IN A, who met the criteria as well as their agreement to be repondents of this investigation. A brief explanation of the purpose and background of the study was given to avoid any misunderstandings. As the students agreed to be interviewed, the possible date, time and venue for the interview meeting were then arranged. On the day of the interview, an informed consent was given to them. They were informed clearly about the purpose of the study and procedures they had to undergo. Besides, no element of coercion towards the respondents to participate in the study. They were allowed to withdraw from the interview session should they feel so. Moreover, all data provided by them are kept confidential. For this reason, each student was addressed with different pseudo name to avoid revealing their true identities.

\subsection{Instrument and Data Analysis}

Semi-structure interviews were used to collect data based on the pre-determined questions prepared at the outset. The respondents were presented with a series of priming questions related to their experience. These questions were framed following the CQ Dimensionality (behaviours and skills) developed by Alon, et.al (2017). In this study, thematic analysis was used for data analysis. Following Braun and Clarke (2006) thematic analysis framework, there were six steps involved in interpreting interview responses which include; (1) familiarising with data, (2) generating initial codes, (3) searching for themes, (4) reviewing themes, (5) defining and naming themes and (6) producing the report. Each interview was transcribed and read thoroughly. The repeated or important points were highlighted and categorized under several codes. The codes referred to small meaningful units of data (label) that were attached to a phrase or short sentence in the interview transcripts. After that, the coded segments were grouped into a more general and abstract form of categorization called category before the themes were created. The themes were reviewed and checked to see whether they matched all the categories assigned. Later, connections between the themes were established. The sample of coding process is shown in Table 3 below. 
Table 2. shows a sample of the coding process

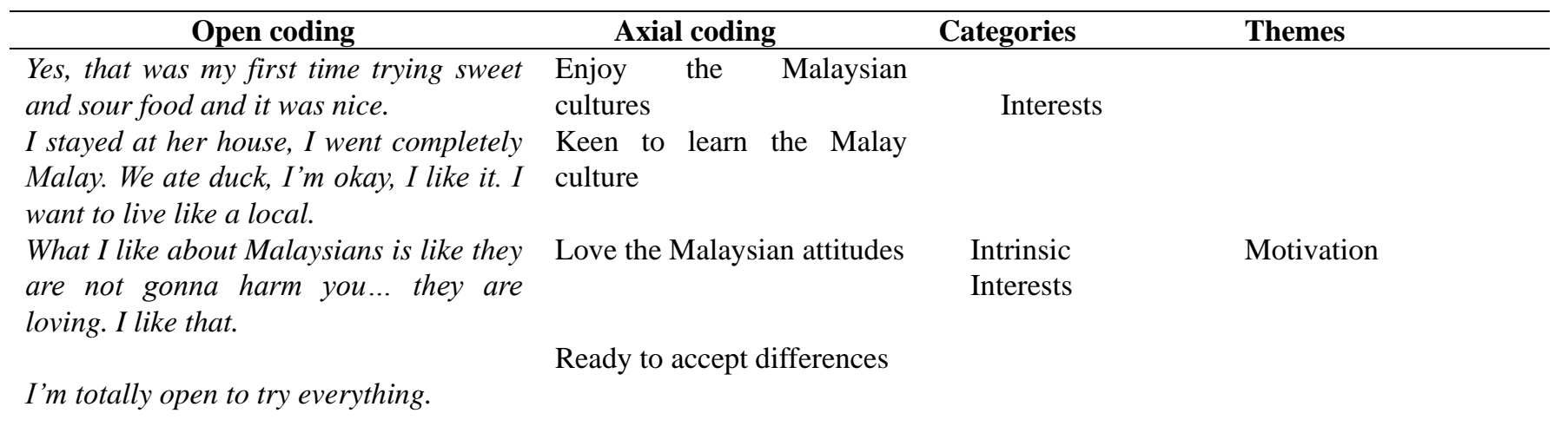

\subsection{Ensuring Trustworthiness and Confirmabilty of the Study}

Trustworthiness is the key value that maintains the validity of the finding. To be accepted as a trustworthy study, researchers are required to get full consent from respondents as informed consent is the major responsibility of the researcher. On the other hand, during interviews, researchers need to be neutral in every possible way to avoid being bias towards the topic discussed. The degree of neutrality was observed to produce a valid research. Probing was done moderately. This is to maintain the respondent's responses without getting distracted by researchers' bias to fit the narrative. Also, researchers need to avoid producing hints or ideas while respondents are responding to the questions because it might change the perception unless they are having difficulties to answer, then it is advisable to help with minor hints.

\section{Discussion of Findings}

Eight themes emerged from the data. These themes were derived from key-word-in-context which were found in the corpus of the transcripts analysed. The respondents' perceptions of cultural diversity were explicated based on two aspects; (1) knowledge and (2) socialisation. Besides, two constructs described the challenges faced by the respondents were (1) internal factors and (2) external factors. Their strategies to be culturally intelligent revolved around the themes; (1) metacognitive, (2) cognitive, (3) motivational and (4) behavioural. The summary of the findings was presented in Table 3 below. 
Table 3. shows the summary of the findings

\begin{tabular}{|c|c|c|}
\hline \multicolumn{3}{|c|}{ Themes } \\
\hline $\begin{array}{l}\text { Perceptions of international } \\
\text { students of cultural diversity }\end{array}$ & $\begin{array}{c}\text { Challenges to be culturally } \\
\text { intelligent }\end{array}$ & Strategies to be culturally intelligent \\
\hline - Knowledge & - Internal factors & - Metacognitive \\
\hline - Cultural information & - $\quad$ Self-preparedness & - $\quad$ Unbiased cultural assumptions \\
\hline & & - Non-judgemental attitude \\
\hline \multirow{12}{*}{$\begin{array}{l}\text { - Socialisation } \\
\text { - } \quad \text { Foreign acquaintances }\end{array}$} & - External factors & - Cognitive \\
\hline & - Locals' attitudes & - $\quad$ Social interaction norms \\
\hline & & - $\quad$ Knowledge on religious beliefs \\
\hline & & $\begin{array}{l}\text { - Understanding of cultural } \\
\text { values/norms/universals }\end{array}$ \\
\hline & & - $\quad$ Socio-linguistics knowledge \\
\hline & & - Motivational \\
\hline & & - $\quad$ Intrinsic interests \\
\hline & & - Intercultural socialisation \\
\hline & & - Behavioural \\
\hline & & - $\quad$ Lifestyle adjustment \\
\hline & & - Verbal adjustment \\
\hline & & - $\quad$ Non-verbal adjustment \\
\hline
\end{tabular}

4.1 Perceptions of International Students of Cultural Diversity in IN A

\subsubsection{Knowledge}

The respondents generally had slight differences in their opinion towards diversity. Fundamentally, they agreed that diversity in the institution is a good platform for them to gain knowledge about the people and places from around the world. They said that they had begun learn to accept and value cultural differences. This agreement was mentioned by PG2, PG3, PG5, PG7, PG10, PG14

\section{PG 2 specifically commented:}

Cultural diversity in this university is a very good thing because you meet people from all walks of life. You get to learn a lot and just see people from different perspectives. That's where you learn to accept the differences (PG2:34)

Besides, PG5 also mentioned:

It's multicultural, so you got to learn about other people not just one.... you know their countries now because your friends [are] from these countries (PG5:40)

The other respondents admitted that diversity comes mainly from international students as the locals at this institution are mainly from the same race (Malays). They only get to see (less interactions) other races outside the university. When asked about Cultural Intelligence, none of the respondents knew or heard about this concept. However, when the researcher explained the basic notion of CQ, some of them admitted that they would have been better prepared as international students to be in a country which is new to them and be better prepared.

4.1.2 Socialisation

Cultural diversity is expected to promote socialisation. Within a culturally-diverse setting, the respondents claimed that they were able to make new friends with the people across the world not just the local students. PG3 added, "It's amazing. It's a lovely country, people are here together and they communicate, socialise and learn from each other. I 
think it's amazing" (PG3:14). Nonetheless, several of the respondents felt that

\subsection{Challenges to be Culturally Intelligent}

\subsubsection{Internal Factors}

The respondent claimed that the challenges they faced during the adaptation process were derived from both the internal and external factors. In regards to the internal factors, they mentioned that they were initially unready to blend in into the Malaysian way of living due to differences in worldview, culture, language as well as differences in education systems.

PG8 said:

I don't understand the concept of sitting on the floor...I think it's part of the culture even in the kampong [village] you can sit on the floor, you sleep on the floor too. For me, I'm not used to it, it's kinda hard to sleep on the floor (PG8:59)

PG6 and PG7 also had similar experience in that they were quite taken aback with the local culture. This made them drew closer to international students, especially from the same continent or from similar countries, notably when it comes to communication and language use. They preferred using the English language rather than learning the Malay language.

Similarly, PG10 added:

...like I said culture shock. There are lots of things that shock[ed] me like Malaysian still having arranged marriage on their own (PG10: 102)

Not only about culture, PG 6, PG7 and PG 9 also pointed out that they had problems eating the Malaysian dishes.

For example, PG5 admitted:

And of course, I have problem with food, this one thing I remember because food here is really spicy and oily and also there's lots of salt (PG5:141)

The issue with food had always been the ultimate challenge for international students in IN A. Although with many international food outlet around campus, the students generally felt that it was not sufficient. Especially PG3 who hailed from South America, making it more difficult for her to find food that suits her.

Besides, PG8 and PG12 agreed unanimously that they disliked 'durian', a type of fruit native to mainly South East Asian. PG 8 lamented:

...one thing I never got used to is durian. I cannot..., the smell...the food here is sweet and spicy. We don't have sweet and spicy. I was shocked (PG8: 82, PG4: 56)

Moreover, difficulty in adjusting to the weather was another problem faced by the respondents. PG6 and PG7 mentioned that they had difficult time adjusting to the local weather, PG 7 said "So that (weather) was very hard for me to adjust. For the first time. I was like, oh, it's very hot in Malaysia" (PG7: 61). Malaysia is hot and humid and many international students coming from countries which experience cold weather find the humidity unbearable.

\subsubsection{External Factors}

The respondents mentioned that there were quite a number of local students who disliked socialising or communicating with international students. They felt that they were often ignored during group works by local students. For instance, PG12 mentioned:

I think the Malaysian students they don't like to work closely with international students... they don't want to communicate with the international students (PG12: 71).

PG9 also described:

...for them [Malaysians] internationals are like outsiders. They also sometimes judge the international students... When I used to be in undergraduate class, every time there will always be group work, Malaysians will always quickly, get into the groups and we were like... which group do I join? It's really hard to break the ice. That was one hard experience during my undergraduate that you had to be alone (PG9:105)

\subsection{Strategies to be Culturally Intelligent}

\subsubsection{Metacognitive}

The strategies used by the respondents in becoming culturally intelligent were explained using the four domains of 
CQ model which included metacognitive, cognitive, motivational and behavioural. The respondents were able to adjust their cultural assumptions besides portraying non-judgemental attitudes towards other people from diverse backgrounds.

PG2 mentioned:

It's important to let them know first instead of to react first...you need to know who you are dealing with and react appropriately (PG2: 111)

Additionally, PG6 also stated:

You have to respect all people here. We know that we are different, mind different, religion different, culture everything. We have to understand and accept each other even if they are totally different. (PG6: 97)

Additionally, PG10 said:

What is important is to be able to accept each other's opinions and to be a good listener. If you're gonna... be judgmental, you quickly gonna... judge people. As long as you do not[ are not] prejudice towards everything. You got to get used to that country, travel and all that, that's important. So that's how I get to know more about people, I let them open up (PG10: 122)

\subsubsection{Cognitive}

The respondents were also aware of the differences and similarities between cultures. With more than a year of living experiences in Malaysia, they were able to comprehend the social interaction norms, cultural values, socio-linguistics as well as the religious beliefs of the locals. All the respondents agreed that the locals were most likely to avoid confrontations.

In relation to this issue, PG9 commented:

I think Malaysians are cool people and kind of quiet and keep to themselves. They are not confrontational. They don't like you to be confrontational or quarrel. If international students have issues with them, they will let you know, but in Malaysia, you are not supposed to do that (PG9:80)

PG1 agreed to the statement that local students are quite 'timid'. He also added:

You cannot find any shouting or fighting here. We can talk like normal right, no need to argue or something but in my country, you can find that a lot. People... they shout (PG1:62)

While PG7 reaffirmed:

We are a bit louder than Malaysians. Malaysians are quiet...I know we cannot speak so openly about politics everywhere here but in my country, people do (PG7:111)

Additionally, several respondents confirmed that they understood the Malaysian cultural values or norms well besides realising the fact that Islam is the official religion. For example, PG8 said:

In my country, we don't smile at people unless you know them. Yes, you can smile at them if they are familiar faces. But here, everyone smiles at everybody...Another big difference is umbrella. In my country, you shouldn't do that, you'll be looking as weird but in Malaysia, it's normal for you to put an umbrella even if it's hot (PG8:127)

In terms of the socio-linguistics knowledge, the respondent were able to list out the differences and similarities between the Malay language and their languages.

PG10 said:

Mmmm... it's totally different because our alphabet, the letters are from Arabic but Malaysia, they are like English... (PG10:55)

PG6 also reported similar comment:

In Malaysia you also have formal, informal, so that's easier. We have 10 different things you have to attach with the females and males, in Malay language it's the same so the gender problem is not there. For us every single adjective, verb, it changes when it comes to gender (PG6:131)

The statement from PG6 above is not uncommon as in Algeria, besides Arabic, they used French as their official communication. 


\subsubsection{Motivational}

The respondents' motivation was another factor which enhanced their adaptability to a new environment. Their willingness to learn about Malaysia could be explained based on the two aspects; (1) intrinsic interest and (2) intercultural socialisation. Clearly, all of them were very motivated that they enjoyed living in Malaysia and were interested to learn the Malaysian cultural practices.

PG5 stated:

I like the food. I try to learn the language. Yes, that was my first time trying sweet and sour food and it was nice. I want to learn, I want to speak (Malay) and learn to cook certain food that I usually eat before I go back to my country (PG5:59)

PG11 also reported similar comments:

I stayed at her [a friend's] house, I went completely Malay. We ate buffalo, I'm okay, I like it. I want to live like a local (PG11: 74)

Meanwhile, PG10 said:

I really like to travel all over the world. I try the culture, be with them (locals), chat with them and communicate. I wanted to be with them to melt in the culture, to feel that (PG10:127)

Apart from the above, the respondent also admitted that they liked to socialise with the locals. They sometimes stayed overnight at their local friend's house to celebrate festivals together.

PG8 mentioned:

Usually I participated in Ramadhan or tarawih...like mauled Nabi, sometimes I went to KLCC. I like that. And for wedding, my Malaysian friend... (PG8:55)

In addition to the above, PG4 commented:

I celebrated Hari Raya here. I went to a local friend house also. I have iftar with my local friend at her house with her family. They know me. I know her mom really well (PG4:71)

\subsubsection{Behavioural (Engagement with the locals)}

The last strategy used by the respondents was behavioural strategy. This was explained based on the three aspects which include lifestyle adjustment, verbal and non-verbal adjustment. For example, all respondents agreed that they were influenced by the locals' fashion style and started to dress like Malaysians.

PG3 and PG7 described their similar experience:

Now I adapted to Malaysian style of hijab. Yeah, that is the change in the clothing (PG7). I wear caps (inner scarf) now, before I didn't (PG3)

Furthermore, the respondents reported that they learned to speak the Malay language besides adjusting their tone while communicating with the locals.

PG9 mentioned:

Because if I speak in the tone I used to speak in my country, I sound very loud because Malaysians speak softly. So yes, I have adapted to that, I adjust my tone (PG9:90)

Correspondingly, the respondents also claimed that they had changed their attitude to suit the Malaysian lifestyle. Besides learning to put more smile, they admitted that they had become more patient and calmer once realising that Malaysians disliked harsh arguments.

PG1 commented:

When I first come here, I realise that being confrontational or direct will not bring any positive changes. So, it kind of to go easy and a little calm and indirect if you want to talk to people sometimes (PG1:101)

PG9 agreed:

...from impolite I become polite. I be[am] more respectful. Especially when I speak to a Malaysian, excuse me sister, Assalamualaikum, Malaysian way of saying it. (PG9: 98)

To sum up, the respondents perceived cultural diversity in their institution as a positive experience that could help them to gain more knowledge about the people and their cultural traditions. As for the challenges, they admitted that they were not prepared initially to adapt to the cultural differences. They ended up making mistakes and failed to 
establish good networks with the locals. On top of that, there were also complaints about the locals' attitudes where they (internationals) were often marginalised and avoided. In addition, all the four mentioned strategies which include metacognitive, cognitive, motivational and behavioural were very important to help the respondent coped with the challenges in becoming culturally intelligent students. As the respondents were able to portray a good understanding of each component or strategy, they were able to adapt well to the Malaysian environment. They were able to adjust their cultural beliefs, understand the Malaysian cultural practices, enjoy discovering new things and were interested to know more about Malaysia besides making few adjustments to ensure a comfortable living in Malaysia.

\subsection{Becoming Culturally Intelligent Students}

To reiterate, the discussion of the findings are framed to the concept of CQ which are metacognitive, cognitive, motivational and behavioural aspects. From the interviews, the respondents perceived cultural diversity in IN A positively where they could enhance their cultural knowledge besides socialising with the people from different backgrounds. Jeannin (2013) reported that cultural diversity could improve cultural awareness by broadening one's knowledge about other cultures besides enhancing the relationship with others. In addition, Corral-Chandler (2014) also supported that a culturally diverse educational setting allowed the students to mix and gain knowledge of other cultures. Moreover, the respondent also shared about the challenges they faced while adapting to the Malaysian environment. From their responses, it was clear that some of the challenges were the result of their lack of preparedness in adapting to the host country which happened during their earlier period in Malaysia. The respondents mentioned that they were not used to the taste of local food which they would always try to avoid (Malaklolunthu and Selan, 2011; Almurideef, 2016). Besides, they also had problems in adjusting to Malaysia's climate which to them was humid and hot (Zuria et al., 2010). However, while many past findings revealed that the ability to converse fluently in English was the main challenge faced by the international students (Unruh, 2015; Alghamdi and Otte, 2016), none of the respondents in the current study experienced similar problem. Besides the issues on personal adjustment, the respondent also reported that they were often avoided by the locals.

One other element discussed in this study was the strategies to be culturally intelligent. The strategies were explained based on the respondents' ability to adjust their cultural beliefs (metacognitive), their understanding of Malaysian cultural practices (cognitive), motivation to learn about the Malaysian cultures (motivational) and the adjustments they made to fit in the Malaysian lifestyle (behavioural). The respondents believed that it is important to respect and accept others' opinions. Being judgemental to others would not help to reduce the gap between the people from diverse backgrounds but to bring one far apart (Flanja and Gâz, 2011). In addition, having an in-depth knowledge about the host country was also helpful for the international students to cope with the different cultural practices (Tseng and Newton, 2002). Apart from that, the respondents too were very motivated to mingle with the locals and learn about their traditions. They were not afraid of the differences rather seeing those as an opportunity to gain new knowledge (Zeng, 2017). Nisreen and Shin (2017) reported that socialisation with the people from different backgrounds really helped one in the adaptation process. To add, as the respondents were highly motivated, they were successful in finding the way out of the problems they faced besides making few necessary changes to suit the Malaysian context. Most importantly, they enjoyed living in Malaysia. Looking at the positive consequences discussed under this theme, the motivational strategy, hence should be regarded a primary factor which helped the respondents overcome the challenges besides ensuring their smooth adaptation process (Harrison and Brower, 2011).

The last strategy was the behavioural strategy. To live happily in a foreign environment was to practice the cultures of the host country where one was able to avoid being ethnocentric (Ersoy, 2014). Many changes had been made by the respondents to conform to the Malaysian lifestyle which defined the acculturation process undergone by all respondents. Undoubtedly, they had become more indirect and more polite when dealing with conflicts. Besides, they also tried to speak the Malay language, dressed like the local people, ate the Malaysian food, spoke softly and many others. Li, et al., (2017) reported that the respondent who were the international students in the U.S changed the way they viewed things as they were somewhat influenced by the American people who were independent and open-minded. It can be said that the latent CQ skills that the International postgraduate possessed, helped them through their adaptation processes during their stay at the host country.

\section{Conclusion}

Being in a foreign country, one can never escape from facing tough challenges due to cultural differences. Denying not to the fact that the respondent too experience difficult times in adapting to the Malaysian environment, it can be said that they are capable in acquiring the CQ skills provided they are open to embracing new cultures and environment. The respondents' viewpoints and perspectives accrued from their daily practices and experiences are 
unique and valuable for them and to the Education Institution Management. Their effort and strong determination to blend in and adapt to the surroundings contribute a lot to their successful adaptability to the host country. Overall, the findings show a positive adaptation from most of the respondents, where they are able to adjust well to their surroundings. Besides, with regards to the strategies used by the respondent, it can be concluded that the motivational strategy is the most important factor which drives the respondents towards a successful acculturation. This is because, to endure hardships while adapting to a new environment will definitely require a strong motivation from within. As the respondents were highly motivated, they learned to shape their cultural beliefs to suit the Malaysian context. They searched for information about the Malaysian cultures and acculturate to the locals' way of living besides enjoying every bit of their lives in Malaysia. Clearly, this study helps to shed light on the importance of CQ on adaptation process. Future studies can be conducted on local students as well as international students' CQ skills and its relation towards academic achievement to further explain the effectiveness of this concept.

\section{Acknowledgement}

This study was supported by the Publication Research Initiative Grant Scheme (PRIGS, 2018) afforded by The International Islamic University Malaysia (IN A). Grant reference no: P-RIGS18-008-0008

\section{References}

Akhtaruzzaman, M., \& Hoque, M. (2011). A Study on Cultural Adaptation of Bangladeshi Male Students at UIA, Malaysia. American Journal of Sociological Research, 1(1), 1-8. https://doi.org/10.5923/j.sociology.20110101.01

Alavi, M., \& Mansor, S. M. S. (2011). Categories of Problems among International Students in Universiti Teknologi Malaysia. Procedia - Social and Behavioral Sciences, 30, 1581-1587. https://doi.org/10.1016/j.sbspro.2011.10.307

Aldhaheri, A. (2017). Cultural intelligence and leadership style in the education sector. Journal of educational management, 31(6), 718-735. https://doi.org/10.1108/ijem-05-2016-0093

Alghamdi, H., \& Otte, S. (2016). The Challenges and Benefits of Study Abroad. International Journal of Humanities and Social Science, 6(5), 16-20. 10.30845/ijhss

Ang, S., Dyne, L. V., Koh, C., Ng, K. Y., Templer, K. J., Tay, C., \& Chandrasekar, N. A. (2007). Cultural Intelligence: Its Measurement and Effects on Cultural Judgment and Decision Making, Cultural Adaptation and Task Performance. Management and Organization Review, 3(3), 335-371. https://doi.org/10.1111/j.1740-8784.2007.00082.x

Baklashova, T. A., \& Kazakov, A. V. (2016). Challenges of International Students' Adjustment to a Higher Education Institution. International Journal of Environmental \& Science Education, 11(8), 1821-1832. DOI: 10.12973/ijese.2016.557a

Berry, J. W. (1980). Acculturation as varieties of adaptation. In A.M. Padilla (Ed.), Acculturation: Theory, models and some new findings (pp. 9-25). Boulder, CO: Westview Press.

Brancu, L., Munteanu, V., \& Golet, I. (2016). Understanding Cultural Intelligence Factors Among Business Students in Romania. Procedia - Social and Behavioral Sciences, 221, 336-341. https://doi.org/10.1016/j.sbspro.2016.05.123

Braun, V., \& Clarke, V. (2006) Using thematic analysis in psychology. Qualitative Research in Psychology, 3(2), 77-101. ISSN 1478-0887. https://doi.org/10.1191/1478088706qp063oa

Chen, S. (2015). Cultural Intelligence, Psychological Well-Being, and Employability ofTaiwan's Indigenous College Students. Review of European Studies, 7(11), 147-155. https://doi.org/10.5539/res.v7n11p147

Cole, Nicki Lisa, Ph.D. (2019, November 8). Understanding Acculturation and Why It Happens. Retrieved from https://www.thoughtco.com/acculturation-definition-3026039

Corral-Chandler, N. I. (2014). Students' Perceptions and Experiences of a Diversity and Inclusion Training Program at a Community College. (Doctoral dissertation, Walden University, USA).

Earley, P. C., \& Ang, S. (2003). Cultural intelligence: Individual interactions across cultures. Stanford, CA7 Stanford Business Books.

Earley, C., \& Mosakowski, E. (2004). Cultural intelligence. Harvard Business Review, 1-8.

Ekelund, B. Z., Cerdin, J., Pekerti, A., Aycan, Z., Thomas, D. C., Au, K., Elron, E., Stahl, G., Ravlin, E. C., Poelmans, 
S., Brislin, R., Maznevski, M., \& Lazarova, M. B. (2008). Cultural intelligence: Domain and assessment. International Journal of Cross Cultural Management, $\quad 8(2), \quad 123-143$. https://doi.org/10.1177/1470595808091787

Ersoy, A. (2014). The Role of Cultural Intelligence in Cross-Cultural Leadership Effectiveness: A Qualitative Study in the Hospitality Industry. Journal of Yasar University, 9(35), 6099-6260. https://doi.org/10.19168/jyu.83730

Evivie, L. G. (2009). Challenges Faced by African International Students at a Metropolitan Research University: A Phenomenological Case Study. (Doctoral dissertation, University of North Carolina).

Flanja, D., \& Gâz, R. M. (2011). Intercultural adaptation: the case of international student exchange programmes. Management and Socio-Humanities, 135-140.

Gardner, H. (1983) Frames of mind: The theory of multiple intelligences. New York: Basic Books

Gapsalamov, A. R., Gallyamova, Z. V., Zakirova, O. V., Ibragimova, E. R., Tarasova, A. N., \& Tirigulova, R. K. (2016). Foreign Students' Adaptation to the Social and Educational Environment of a Small City as a Condition of Undergraduate Teachers' Cultural and Professional Competency Formation. International Forum on Teacher Education, 2, 404-410. https://doi.org/10.15405/epsbs.2016.07.64

Gebhard, J. G. (2012). International Students' Adjustment Problems and Behaviors. Journal of International Students, 2(2), 184-191. https://doi.org/10.32674/jis.v2i2.529

Harrison, J. K., \& Brower, H. H. (2011). The Impact of Cultural Intelligence and Psychological Hardiness on Homesickness among Study Abroad Students. The Interdisciplinary Journal of Study Abroad, 41-55. https://doi.org/10.36366/frontiers.v21i1.303

International Islamic University Malaysia, (2018). Background. Retrieved on March 18, 2018 from http://www.iium.edu.my/page/background-6

Jeannin, L. (2013). Students' Perception of Diversity in an International Classroom. Higher Learning Research Communications, 3(4), 6. https://doi.org/10.18870/hlrc.v3i4.165

Khatiwada, S. (2012). Barriers Faced by South Asian International Undergraduate Students Pursuing Higher Education in the USA. (Honors Thesis, University of North Carolina).

Idrus, F. (2015). Examining classroom transformational spaces using the third space theory in developing students' sense of shared identity. Theory and Practice in Language Studies, 5(1), 28-37. https://doi.org/10.17507/tpls.0501.04

Idrus, F. (2014). Initiating Culturally Responsive Teaching for Identity Construction in the Malaysian Classrooms. English Language Teaching, 7(4), 53-63. https://doi.org/10.5539/elt.v7n4p53

Li, Z., Heath, M. A., Jackson, A. P., Allen, G. E., Fischer, L., \& Chan, P. (2017). Acculturation experiences of Chinese international students who attend American universities. Professional Psychology: Research and Practice, 48(1), 11. https://doi.org/10.1037/pro0000117

Lin, S., \& Scherz, S. D. (2014). Challenges Facing Asian International Graduate Students in the US: Pedagogical Considerations in Higher Education. Journal of International Students, 4(1), 16-33. DOI: https://doi.org/10.32674/jis.v4i1.494

Lin, J.-C. G., \& Yi, J. K. (1997). Asian international students' adjustment: Issues and program suggestions. College Student Journal, 31(4), 473-479

Lovvorn, A. S. (2011). Developing a Global Mindset: The Relationship between an International Assignment and Cultural Intelligence. International Journal of Business and Social Science, 2(9), 275-281.

Malaklolunthu, S., \& Selan, P, S. (2011). Adjustment problems among international students in Malaysian private higher education institutions. Procedia Social and Behavioral Sciences, 15, 833-837. https://doi.org/10.1016/j.sbspro.2011.03.194

Ng, K.-Y., Van Dyne, L., \& Ang, S. (2009). From experience to experiential learning: Cultural intelligence as a learning capability for global leader development. Academy of Management Learning Sr Education, 8, 511-526. https://doi.org/10.5465/AMLE.2009.47785470

Nisreen, A., \& Shin, S. (2017). Factors Affecting the Academic and Cultural Adjustment of Saudi International Students in Australian Universities. Journal of International Students, 7(1), 53-72. https://doi.org/10.32674/jis.v7i1.245 
Nur Arief, R. P., Aurik, G., \& Achmad, G. (2015). Analysis of Cross Cultural Management Course Pedagogy Methods in Developing Students' Cultural Intelligence. Procedia - Social and Behavioral Sciences, 169, 354-362. https://doi.org/10.1016/j.sbspro.2015.01.320

Ott, D., L., \& Michailova, S. (2018). Cultural Intelligence: Review and New Research Avenues. International Journal of Management Reviews, 20, 99-119. https://doi.org/10.1111/ijmr.12118

Paltridge, T., Mayson, S., \& Schapper, J. (2012). Covering the gap Social inclusion, international students and the role of local government. Australian Universities'Review, 54(2), 29-37.

Pare, J., \& Tsay, W. (2002). A Study of the Adjustment Process of International Students within the Taiwanese Institutions of Higher Education. Journal of China University of Science and Technology, 1-29.

Peterson, B. (2004) Cultural intelligence: A guide to working with people from other cultures. Boston, MA: Intercultural Press

Ramalu, S. S. Wei, C. C., \& Raduan, C. R. (2011). The Effects of Cultural Intelligence on Cross-Cultural Adjustment and Job Performance amongst Expatriates in Malaysia. International Journal of Business and Social Science, 2(9), 59-67.

Solomon, A., \& Steyn, R. (2017). Exploring cultural intelligence truths: A systematic review. SA Journal of Human Resource Management, 15, 1-11. https://doi.org/10.4102/sajhrm.v15i0.869

Sternberg, R. J. (1986). A framework for understanding conceptions of intelligence. In R. J. Sternberg \& D. K. Detterman (Eds), What is intelligence? Contemporary viewpoints on its nature and definition (pp. 3-15). Norwood, NJ: Ablex.

Stockert, J. P. (2015). Expatriate Adjustment of U.S. Military on Foreign Assignment: The Role of Personality and Cultural Intelligence in Adjustment. (Master's thesis, Minnesota State University, Mankato).

Thomas, D. C. (2006). Domain and development of cultural intelligence: The importance of mindfulness. Group \& Organization Management, 31(1), 78-99. https://doi.org/10.1177/1059601105275266

Thomas, D. C., \& Inkson, K. C. (2009) Cultural intelligence: Living and working globally. San Francisco: Berrett-Koehler.

Tseng, W., \& Newton, F. B. (2002). International students' strategies for well-being. College Student Journal, 36(4), 591-596.

Unruh, S. (2015). Struggling International Students in the United States: Do University Faculty Know How to Help? Athens Journal of Education, 2(2), 99-109. https://doi.org/10.30958/aje.2-2-1

Yusliza, M. Y., \& Chelliah, S. (2010). Adjustment in International Students in Malaysian Public University. International Journal of Innovation, Management and Technology, 1(3), 275-277.

Zeng, D. (2017). Cultural Adaptation in International Students: Risk Factors and Protective Factors. TuftScope, 16(2), 38-39.

Ziyatdinova, E. (2017). The Role of Cultural Intelligence from the Perspective of Leader. (Degree's thesis, Arcada University).

Zuria, M., Salleh, A., Saemah, R., \& Noriah, M, I. (2010). Challenges for International Students in Malaysia: Culture, Climate and Care. Procedia Social and Behavioral Sciences, 7(C), 289-293. https://doi.org/10.1016/j.sbspro.2010.10.040

\section{Copyrights}

Copyright for this article is retained by the author(s), with first publication rights granted to the journal.

This is an open-access article distributed under the terms and conditions of the Creative Commons Attribution license (http://creativecommons.org/licenses/by/4.0/). 